\title{
Building the Big Picture: A comparison of First Year Design Courses in Engineering and Industrial Design
}

\author{
Brian Burns and Ron Britton \\ Associate Professor, School of Industrial Design \\ Carleton University \\ Associate Dean (Design Education, Faculty of Engineering) \\ University of Manitoba \\ brian_burns_eng@carleton.ca \\ ron_britton@umanitoba.ca
}

\begin{abstract}
For the student entering engineering and associated design degree programs the challenge to master the range of fundamental knowledge skills is considerable in itself. In most disciplines the knowledge base on which student courses are constructed is both changing and growing at an increasing rate. As a result it is now difficult for any student to see how these technical, scientific and mathematical courses fit into the big picture of the discipline they plan to become part of. Their high school experience is limited to general awareness at best, but is largely focused on fundamental sciences. This is obvious in engineering, but is possibly more problematic for a student interested in industrial design, with the same core mathematics and physics requirements, yet often without the appropriate visual and creative courses.
\end{abstract}

Additionally, first year students come from a range of backgrounds, which makes the initial courses relating core material to their chosen professions more difficult to focus.

This paper details the work of two introductory first year courses - An Engineering course from the University of Manitoba is compared and contrasted with a Design Studio Course in the School of Industrial Design at Carleton University. In both courses the range of projects given may at first glance seem quite simple, but each has been designed and developed to build the bridge of understanding between fundamental skills and the profession it leads to. Both courses try to take full advantage of the opportunities the projects present within the limited time available.
Success in such courses is usually achieved by ensuring that every project/challenge is not seen as 'the design of a new something', but that it is couched in an understandable reality. This might be achieved by the design process the students are expected to go through, the context in which the design challenge is set, the history and evolution that brought the project to this particular stage, the significant economic, social and business drivers, and of course the fundamental skills and knowledge base being developed.

The aim of this paper is to help identify a pattern that other first year engineering/design courses could adopt or modify, as the challenge of 'Building the Big Picture' become more essential.

\section{Introduction}

There is a perception that design projects, particularly open-ended ones, are very time consuming - this is true. There is also a perception that there is a growing gap between the student's awareness of the 'real world' they will be spending their careers in and the fundamental knowledge (maths, material science, physics, etc) that must be absorbed along the way this appears also to be true. Fitting everything into a highly regulated four year program is difficult, yet there can be no denying that students will encounter open-ended projects rather than multiple choice exams in their future careers. The creative challenge is to find ways in which projects can be used to bridge the gap in an expedient way. 


\section{Why Projects?}

Educational programs offer considerable contrast to projects found in the work-place. Courses must start and end at a certain time, they must be equitable and examinable, they usually require predictable correct answers, and they often require a text book, which may be technically up-to-date but completely lack relevant context. It is obvious how exam papers, sample questions and a tendency to fall back on the tried and tested have resulted.

Design projects with a hint of an open-ended or multiple solutions appear to demand individual attention. The equipment and materials might be hard to assemble. These are valid causes for concern, yet schools of all the design disciplines employ design projects throughout their programs and have evolved ways in which 'real world' context can be imbued into every project. Projects, or particularly design projects, are in themselves limited. In school, projects must start and end on time, and hopefully end successfully. In the 'real world' many projects never reach their ultimate conclusion. Projects are stopped for technical and financial reasons at any point, but the model they present is still the best we have. The challenge is to learn how to design the design projects. Short projects, long projects, individual and team projects, partial, conceptual, detailed, futuristic, cost-saving projects; all are options to be adapted to fit pedagogical needs and timeframes.

\subsection{Changing Projects}

It often takes years to develop a good project, even when modifying it slightly every year. Most design programs offer patterns of projects, with clearly identified skills and lessons, that are repeated, with a twist, every year. The message here is that good projects need not be thrown-away every year, in the blind belief that a completely new project needs to be developed for next year.

Change is inevitable, but it is key to identify why the change is being made.

\subsection{The 'Current' Project}

For many faculty the age and interests of the students are difficult to grapple with. For most students history is just that; they are interested in the future, and the latest technology.

While designing for the future certainly limits the examinability of a project, the near future, with an appropriate reference to the best of traditional technology makes for the best design project objective. This is less difficult to plan for. However, the experience of faculty relies heavily on tried and tested approaches. The need for 'currency', in fact, be addressed simply by careful consideration of the project's context.

What follows is a review of two distinct approaches to the challenge of initiating design awareness in first year students.

\subsection{Carleton's Industrial Design Approach.}

The Study of Industrial Design offers perhaps the closest reference to that of engineering, with similar academic demands in maths and physics, but with the need for a demonstrable creative portfolio. Students in first year will take courses in maths, physics, design history and design analysis, but there will always be the design studio course....and the students want to design.

Carleton University is not untypical, and the program is well established in bringing the fundamentals to first year students. The course referenced here is a one year course with a 1.5 hour lecture component and four hours per week of studio design time. Students are expected to work a further 4 hours each week on their own time.

\subsection{The Carleton Industrial Design Course}

\section{Basic Course Description:}

An introduction to the skills and processes of industrial design; including drawing and sketching as an aid to design (including technical drawing), the basics of line and shape, ideation and visualization, product drawing and presentation techniques, an introduction to basic model-making practices and equipment, and an introduction to the design process. This introductory studio exposes students to the skills required to undertake design project courses and introduces them to core material taught in the other courses of the School of Industrial Design undergraduate program.

Students are expected to -

- gain an awareness of basic visual construction techniques;

- develop a basic understanding of line, form and colour theory;

- become familiar with the basics of the design process; 
- make perspective sketches using both freehand and measured-perspective systems and utilize these skills for the development of ideas;

- become familiar with the norms and nomenclature of technical drawings;

- make assembly and dimensioned part drawings;

- make quick perspective sketches;

- undertake fundamental design projects in two and three dimensions.

Note: There is also a list of tools and materials that students are required to have available costing approximately $\$ 200$. There is also a prescribed sketch book (Blank 11”x14”). The course has approximately 40 students is generally taught by one professor without the aid of teaching assistants.

\subsection{The Projects}

Projects vary in length from a few hours to a few weeks, and many overlap in time with each other.

1. The first exercise gets the whole class to consider the redesign of a Parking Meter, based on concerns for theft, slots being abused, the need for street cleaning, cost of installation, and concerns for blind pedestrians. After one hour students are required to present their thoughts and ideas. The project introduces them to a broad range of facets that are key to any design project. The project ends with exposing the students to the latest ways of paying for parking in other parts of the world, and a short detailed drawing challenge.

2. On a standard sized sheet (8.5x5.75”) students morph the form of a product in five stages from one model to another, e.g. from a hand drill to a power drill.

The first two projects carry no marks.

3. Following lectures in perspective and basic drafting students are given the challenge of designing an electric flat-bed vehicle adapted for a specific purpose, e.g. airport passenger transportation. They are then required to consider basic ergonomics and manufacture in the completing a perspective visual and a General Arrangement drawing. The project concludes with the design of a wooden toy version of their vehicle, requiring visuals, a GA and simple wood part drawings. The class' favourite toy is then constructed from their drawings in the woodshop by our technicians.

There are sketching challenges given along the way with lectures on technique with demonstrations, but always with a product context.

4. In alternating years the class draws, under a common theme, either a calendar or a deck of playing cards. Both are manufactured in quantity and students buy approximately 5 each at cost for gifts at the end of the fall term.

5. As an introduction to the design and manufacturing process, each student designs and makes plans for a flat-pack piece of cardboard furniture, able to take their own weight. Each student then makes the pieces of another student's design from their plans. Each student is then required to assemble the pieces of another design using the assembly instructions (without written words) and visuals of the original designer. Each student produces a learners report based on their perception of the exercise. This project overlaps several of the other projects and the in-class sketching exercises.

6. As a further introduction to ergonomics and tools, each student is required to produce a drawing showing a hand holding a specific tool.

7. Students hand paint a colour wheel to accompany lectures on basic colour theory.

8. By the end of the term every student's sketchbook will have been reviewed twice, with comments.

The second (winter) term acts as a continuation with attention to specific design skills.

1. The course begins with a visit to The National Museum of Science and Technology to learn more of the history and evolution of products, and to be exposed to the process of Exhibition Design. Students then produce a poster (hand-drawn) based on the evolution of one particular project e.g. the camera. The posters are intended to be sold in the museum store. 
2. As an introduction to the workshops and model making, students are given two dynamic projects. The first over only three hours, is to produce a device made from scraps to be powered by elastic bands to enable a device holding a ping-pong ball to undertake a simple task e.g. bounce over a two beams and go on to hit a bowling pin. This is the precursor of a second challenge to keep a ball bearing in motion for 10 seconds on a device that will ultimately light a match. This task usually requires a truth to materials approach with variations on theme and size of device. Like many projects this is followed by a learners report.

3. Two tasks are undertaken in unison, in teams of two. The first involves the photographic documentation of an existing product (say, a toaster) and its use, to communicate it to someone from another place or planet. The second introduces the students to the basics of 3 software packages over three weeks - Adobe Illustrator, Photoshop, and Solidworks. The exercise is to design a wall clock for a particular corporation. All students produce their version of their clock; some are printed in 3D.

4. To further develop drafting skills and knowledge of typical hardware, students are sent to purchase a piece of hardware that acts as a connector e.g. a drawer pull, and to create a technical drawing which fully explains its dimensionality and its use.

5. Form is introduced through a 4 hour project in which thin polypropylene sheets are cut into shapes that form either a candle shade or a decorative LED light cover. Students submit photographs to show the desired visual effect.

6. As with the first term, the sketch book is reviewed twice to help develop technique and approaches to research and design development.

Much of the work of the first year is an introduction to courses and skills that will be developed further in greater detail in later courses, however all the projects are put into a real context, which demonstrates the many ways and fields in which design is used. The goal is fundamentally to raise awareness of the design process, teamwork, context, and the appreciation of 'good' design.

\subsection{Manitoba’s Engineering Approach}

Typically first year Engineering students tend to be high achievers in both math and science. They do not think of themselves as creative, but rather they focus on "correct" answers to specific questions. They are technologically savvy, and anticipate that they will use increasingly complex technology to address scientific questions. Their individual success in the math and science classes in high school has shaped their understanding of how their future work will develop. The Design in Engineering class was developed to provide a first exposure to design within the 'real world' engineering context.

\subsection{The Manitoba Design in Engineering Course}

ENG 1430, Design in Engineering, is a 3-credit required first year course. It involves 2 one-hour lectures and a 2 hour laboratory. It is intended to provide students with an understanding of the design process and its elements from an engineering perspective. The process is placed in the context of the structure of the Engineering profession.

\subsection{The Course Description}

"The Creative Process; the Design Process; Working in a Team. The Engineering Profession from the perspective of students and professionals. Academic, Legal and Ethical considerations.”

The class is delivered by one Instructor, two Engineers-in-Residence and one Teaching Assistant. All four persons attend all class sessions. $\mathrm{r}$

With class sizes in the order of 80 students, each class is subdivided into 16 design teams. The teams are selected by the instructor. The course is delivered in a design studio with electronic lecture delivery capabilities and furnished with moveable round tables and chairs.

Initially students resist the idea of working in teams. In general, their past experience has not been positive. Therefore, significant effort is directed toward helping them learn how teams are supposed to work. The Engineers-in-Residence provide much of this coaching given that they have the credibility of coming from the 'real world'. 
Lectures address the full range of topics from the course description. In order to encourage student participation, an electronic response system (the iclicker) is used to track student response to questions posed. As well, the i-clickers are used to record student and team responses to minitests that form a part of the Team Learning technique employed during the lectures. Minitests cover both lectures and reading assignments.

The classes are scheduled so that one of the lectures is held in the hour preceding the laboratory. This provides flexibility is classroom use and allows lectures and laboratories to "blend" depending on learning requirements rather than academic scheduling.

The prime focus on the design process is concentrated in laboratory periods. Students are given responsibility for the operation of their teams. They are provided guidance in the conduct of meetings, maintenance of personal journals. The most onerous element of this responsibility relates to attendance. Attendance is mandatory, with loss of marks for absences. However, each design team is given six (6) "Excused Absence" forms. If a student is absent with cause, his/her teammates can complete a form on the absentee's behalf, and no penalty will be assessed.

There are five specific design projects associated with the course.

1. the design, construction and testing of a tower to support a $10 \mathrm{~kg}$ mass. The towers are fabricated using standard "file cards" and masking tape. Teams evaluate their designs after testing and can rebuild and retest. This takes one laboratory period.

2. the presentation of a design concept on a single sheet of "flip chart" paper using an "ink marker". There is a limit of 10 words, with numbers counting as "words". This occupies a part of two laboratory periods.

3. the design, construction and testing of a rubber band powered "car". Each team is supplied with the rubber band that must be used as the only source of power and a set of design/performance constraints. Work on this project takes three laboratory sessions, all of which are "extended" by limiting the length of the lecture.
4. the design, fabrication and demonstration of a three story elevator controller. Students receive a one hour introductory lecture on circuit logic. Each team is provided with a "package of "parts" and a breadboard. Again, this requires three laboratory sessions.

5. the design, fabrication and demonstration of an "egg mover". The objective is to move a raw egg through a distance of 16 feet, over a $2 \times 6$, and place it on the centre of a bulls eye. Students are only supplied with the design constraints. On the day of testing, eggs are supplied by the instructor.. This is the third three week project.

Specific details of each project are changed each year to avoid the use of accumulated "corporate" memory. By "tweaking" projects requirements rather than introducing new projects, we can be assured that the demands on student time, both in and outside class, are predictable and fair.

The grading system is based on both meeting the performance criteria and "evaluation" by the other teams. Evaluation criteria are provided on the day of testing. Typically they are very qualitative in nature (for example assess aesthetic appeal) to force consideration beyond the technical or numeric. Laboratory grading places importance on participation. Once the combined performance grade and student evaluation grade is totalled, the highest total is assigned 10/10. The lowest total is assigned a grade of 7/10. Other totals are ranked between these two extremes. Non participation is assigned a $0 / 10$. In this way, students are encouraged to take risks in their designs because the only serious negative impact is not participating.

Throughout the course, mini workshops on brainstorming, journal preparation, meeting procedures, team work and professional "behaviour" are conducted during laboratories. Given that the objective of the course is to help students understand that they are on the first step toward a professional career, we incorporate both skills and expectations into the classroom environment. In particular, we stress, at the student's frustration and ours, the importance of being on time.

Beginning with the second lecture in the term, students receive a feedback sheet entitled "Things I would try to remember". This includes a summary of the points the instructor was attempting to make, a 
list of "jargon" words, and their definitions, that were introduced in the lecture, a "mind game" of some sort, and any messages that may be appropriate.

Given the importance of "speaking the language", a crossword puzzle based on the accumulated list of "jargon" is included on the final exam. Students are advised of this in the first class and reminded periodically during the term.

Project based courses with a lecture component provide opportunities to deliver "messages" within the design context. The problem, from an instructor's perspective, is knowing if the "messages" were "received". After each lecture, an assigned number of teams are required to prepare, and submit, as many as four multiple choice or true/false questions based on that specific lecture. Selected questions are used on the final exam.. With 32 teams per term, this provides both a broad range of questions for the exam and immediate feedback to the instructor. The questions are posted weekly so all students have access.

First year students do not have the technological base required to produce refined designs. On the other hand, they quickly learn that they can produce working units using the design process. It is interesting to observe the shift in their attitudes toward creativity as they come to realize that can develop something "new" in response to a vaguely posed problem. Our goal of helping students gain an understanding of both the design process and the environment in which design is carried out seems, in most cases, to be attainable.

\subsection{What do they have in common?}

Both courses have clear common goals - to expose students to designing and the design process. Interestingly all students who participate well in the courses are successful. At the first year level there is a strong expectation that students will continue to grow in the remainder of their program, and it may take two or three years before the students become aware of the lessons they have learned.

Both courses attempt to demonstrate how they relate to the courses that will follow in their respective programs.

There is good agreement that taking a well developed project and 'tweaking' it each year offers appropriate assurance that it can be successful in the time available, while seen by the students as current.
All students are grade sensitive, and both courses have evolved means of marking and grading which help the students to understand the elements of the design process. In Industrial Design all projects are reflected upon in in-class reviews or by learning reports; grades are awarded against a series of attributes. In general an effective design solution is only half of the mark, the other half is reflected in the process and the quality of the deliverables. In Engineering marks are assigned based on performance criteria and "evaluation" by the teams. The assigned grades reflect the relative overall marks with a minimum grade that decreases the risk of "taking a chance". After each project specific reviews are conducted by the teams and general inclass reviews reflect on "lessons learned".

An important part of both courses is the introduction of jargon. All professions have their own jargon as a means to communicate subtle elements of their work. By developing a knowledge of such jargon, students are encouraged to be able to discuss their progress and their rationale for their solutions.

All projects are intended to put aspects of designing into clear perspective, and it is interesting how such problems enable the teaching and discussion of many real-world issues. Discussion of design commonly touches on issues of ethics and professionalism, as well as business and marketing, and, at times, personal philosophy. The apparent open-endedness of design projects offers vital pedagogical opportunities not found in more closed technical subject courses. Learning from each other is far more likely when students can explore differing solutions.

All design challenges in both courses follow a process; apparent failure at one stage leads to learning, as the next stage is undertaken. This also strengthens the need for courses to have several projects, some as short as an hour; to foster learning without putting all the design eggs in one basket. Not surprisingly the different programs have different strengths. The engineering projects are, likely, far more successful in developing precise performanceoriented solutions; however the notion of aesthetics is more evolved in design school approaches. In industrial design the term 'technological elegance' can be used to judge the efficacy of a solution, while reflecting on 'perceived added value' which is more concerned with looking good (or cool) rather than actually being a better solution. Engineering currently tends to struggle with such distinctions, but well conceived projects do foster such discussions. 
Finally it would be foolish to expect engineering and industrial design courses to be the same, but this exercise has shown the importance of putting projects, no matter how simple, into an appropriate context. The opportunities that result in a well controlled yet somewhat open-ended design challenge are invaluable. The continuous building of knowledge of both design process and context, so far from the perceptions of graduating high school students, is vital for degree students to be successful in their careers. Designing appropriate design courses is the on-going challenge. 